\title{
Subhepatic Appendicitis in North-East India: A Case Series Analysis and Review of Literature
}

\author{
Ranjan Kumar (iD) ${ }^{1,}{ }^{,}$, Thokchom Biswajit Singh ${ }^{2}$, Rahul Pandey (iD ${ }^{1}$ and Sandeep Bhalla (iD ${ }^{3}$ \\ ${ }^{1}$ Surgery, Base Hospital Tezpur, India \\ ${ }^{2}$ Surgery, Military Hospital Ambala, India \\ ${ }^{3}$ Community Medicine and Commandant, Base Hospital Tezpur, India \\ "Corresponding author: Surgery, Base Hospital Tezpur, India. Email: ranjan_afmc@yahoo.co.in
}

Received 2021 May 21; Accepted 2021 October 12.

\begin{abstract}
Acute appendicitis is one of the common surgical emergencies performed by general surgeons. The abnormal position of the appendix may cause a diagnostic dilemma for the treating surgeon. A high index of suspicion along with radio imaging can prevent the delay in the diagnosis and the associated complications of the disease. We report a case series of sub-hepatic appendicitis managed at two different institutions in North-East India and advocate surgical management as the modality of treatment for this condition.
\end{abstract}

Keywords: Acute Appendicitis, Ultrasonography, Computed Tomography

\section{Introduction}

Acute appendicitis is a common clinical condition, and appendectomy accounts for about $1 \%$ of all surgical operations (1). Normal appendix anatomy and its classical presentation are well documented, but there are many aberrations necessitating a high index of suspicion and awareness of these anatomical variants to correctly diagnose and safely manage appendicitis (2).

We report a case series of subhepatic appendicitis managed at two different institutions and advocate surgical management as the modality of treatment for this condition.

\section{Case Presentation}

\subsection{Case 1}

A 32-year-old male patient presented with recurrent episodes of diffuse pain in the right upper abdomen and flank for the past six months with a present episode of pain since two days before hospital admission, which was associated with nausea and anorexia. There was no history of fever or urinary or gastrointestinal symptoms. The patient had been evaluated by ultrasonography (USG) thrice in the last six months, which showed normal results. On examination, the patient was hemodynamically stable and afebrile. On examination, the abdomen was soft, and tenderness was present on deep palpation in the right upper quadrant and flank, and rebound tenderness was present over the right upper quadrant.

All the routine laboratory investigations were normal, except TLC: $14,100 / \mathrm{mm}^{3}$ DLC - P80, L15. Ultrasonography of the abdomen was normal. Non-contrast computed tomography (NCCT) of the abdomen showed thick and dilated appendix in the subhepatic position with fat stranding (Figure $1 \mathrm{~A}$ ). The patient underwent lap appendectomy under general anesthesia. Intra-operative findings included an 8 -cm inflamed appendix in the subhepatic location and caecum in the subhepatic position (Figure 1B). The postoperative period was uneventful, and histopathological examination report was consistent with chronic appendicitis.

\subsection{Case 2}

A 28-year-old male patient presented with complaints of insidious onset pain in the right lower quadrant of the abdomen, which was associated with low-grade fever, nausea, and vomiting. On clinical examination, he had tachycardia and fever (temperature: $100.2^{\circ} \mathrm{F}$ ). Abdominal examination revealed tenderness in the right iliac and lumbar region, and rebound tenderness was present in the right flank. Psoas sign, obturator sign, and Rovsing's sign were negative. Investigations showed TLC of $13,100 / \mathrm{mm}^{3}$, with shift to the left. Abdominal ultrasonography showed small collection in the right iliac fossa, but the appendix was not visualized. No calculi were visualized in the kidney or 

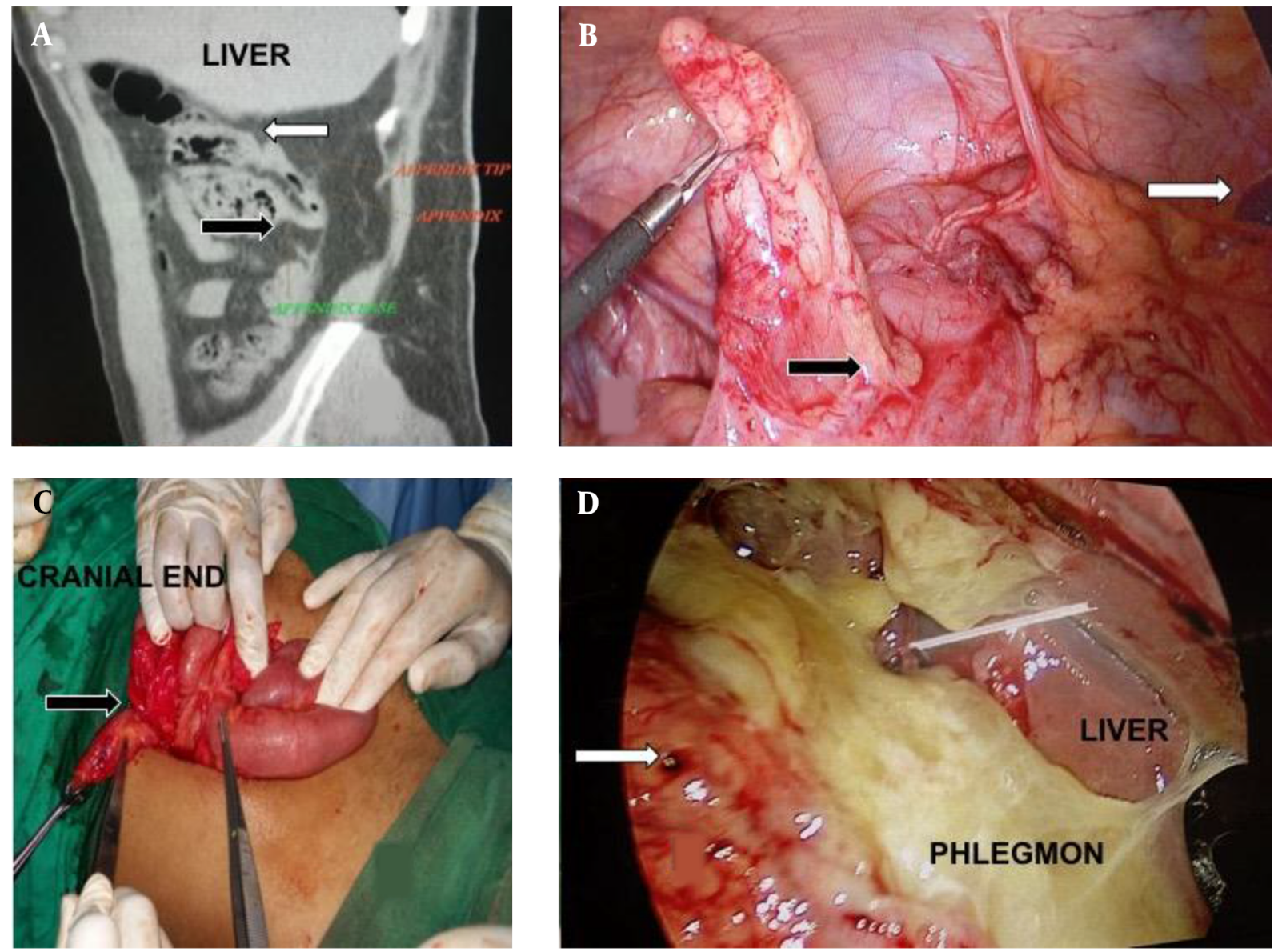

Figure 1. (A) NCCT abdomen sagittal section showing the subhepatic location of the appendix, the black arrow marking the base, and the white arrow marking the tip of the appendix, which is reaching till the subhepatic location. (B) Appendiceal critical view with the black arrow marking the Ileo-caecal junction and the white arrow pointing towards the right lobe of the liver. (C) Intraoperative picture showing the extension of the McBurney's incision cranially (covered by the bowel loops) with the black arrow indicating the subhepatic position of the base of the appendix. (D) Intra-operative picture of the appendicular lump, with the white arrow marking the perforated tip of the appendix, which was lying in the subhepatic position.

ureter. The gall bladder and liver were normal. The kidney, ureter, and bladder X-ray was normal. The diagnosis of acute appendicitis was based on clinical and Alvarado's score.

The patient was taken up for open appendectomy. McBurney incision was given; on exploration, the right iliac fossa was empty. The incision was extended, and the appendix was found near the inferior border of the liver along with pulled up caecum (Figure 1C). Appendectomy was performed, and the post-op period was uneventful. The histopathological report was consistent with acute appendicitis.

\subsection{Case 3}

A 32-year-old male patient presented with pain in the periumbilical region of four days duration, which mi- grated to the right flank. It was associated with a highgrade fever of two days duration. He also complained of vomiting, mild abdominal fullness, and loss of appetite. He did not report any history of constipation or jaundice. On examination, the patient was toxic looking, with pulse: (1) 112/min, (2) BP: $96 / 70 \mathrm{mmHg}$, and (3) temperature: $102^{\circ} \mathrm{F}$. On abdominal examination, the right upper and lower quadrants were tender; guarding was present in the right hypochondrium. Investigations showed $\mathrm{Hb}: 15.6 \mathrm{gm} / \mathrm{dL}$, TLC (Total leucocyte count) $16,500 \mathrm{~mm}^{3}$, DLC: P90L06. Ultrasonography of the abdomen and pelvis was suggestive of fluid in the pelvis and bowel edema.

In view of clinical features of early peritonitis, the initial resuscitation decision was made for diagnostic laparoscopy. The diagnostic laparoscopy revealed (a) phlegmon and pus flakes in the parietal peritoneum in the right 
hypochondrium, (b) small bowel adhesions along with the adhesion of small bowel with the omentum and parietal peritoneum in the subhepatic region, and (c) $20 \mathrm{~mL}$ pus in the pelvis (Figure 1D). Adhesiolysis was performed using blunt dissection; gallbladder, stomach, and the visualized portion of the duodenum were found to be normal; caecum was pulled up in the subhepatic region, and the tip of the appendix was visualized, which was perforated. Appendectomy was attempted, but due to dense adhesions and failure to visualize the base of the appendix, the procedure was abandoned. Peritoneal lavage was done, and subhepatic abdominal drain was placed. The abdominal drain was removed on the fourth post-operative day, and parenteral antibiotics were stopped on the tenth post-operative day. Interval appendectomy was performed after eight weeks, and intra-op appendix was found in the subhepatic position. The histopathological examination was consistent with chronic appendicitis.

\section{Discussion}

Acute appendicitis is the most common cause of acute abdomen in young adults. Appendectomy is the most frequently performed urgent abdominal operation by general surgeons (3). The diagnosis of appendicitis is essentially clinical, with the advances in modern radiographic imaging improving the diagnostic accuracy. Various anatomical positions of the appendix are well established, which in the decreasing order of incidence include retrocaecal $(74 \%)$, pelvic (21\%), paracaecal $(2 \%)$, subcaecal (1.5\%), preileal (1\%), and postileal (0.5\%) (3).

At any age of presentation, variation in the location of the appendix due to adhesions or developmental anomalies leads to a non-typical presentation, delay in diagnosis, and increased morbidity associated with the disease (4). Subhepatic appendicitis was first described by King in 1955 (5). The incidence of subhepatic position of appendix is $0.08 \%$ (6). The subhepatic position of the appendix is due to a developmental anomaly resulting from failure in the descent of the caecum during the embryonic development (7). One study has reported intestinal malrotation rather than non-descent of the caecum as the cause of this anatomical variant (8). Subhepatic appendicitis often has higher complication rates due to its delayed diagnosis $(1,5)$. Subhepatic appendicitis may be mistaken for other conditions like acute cholecystitis, pyelonephritis, and urolithiasis. Late diagnosis of sub-acute appendicitis leads to complications like appendiceal perforation and abscess, pyelonephritis, and hepatic abscess $(1,4,5,9)$.

Computed tomography and USG imaging are the preferred imaging modalities for the diagnosis of abdominal pain and appendicitis (10). Studies comparing the two modalities for appendicitis reveal increased accuracy with CT over US, and equivocal cases have demonstrated CT to be more accurate $(10,11)$. Ultrasonography has a reported diagnostic accuracy of 90\% (12). Ultrasonography findings suggestive of acute appendicitis include thickening of the appendiceal wall, loss of wall compressibility, and increased echogenicity of surrounding fat (13). It has the advantage of widespread availability and avoidance of exposure to radiation and ionizing contrast; however, it is highly operator-dependent (13). For most adult patients with abdominal pain and suspected appendicitis, abdominal CT has become the main diagnostic imaging study with an accuracy of greater than $94 \%(10,14,15)$. Computed tomography findings suggestive of acute appendicitis include dilated ( $>6 \mathrm{~mm}$ ), thick-walled appendix that does not fill with enteric contrast or air, and surrounding fat stranding (13). In situations where abdominal CT is inconclusive and the clinical diagnosis of appendicitis is doubtful, diagnostic laparoscopy is recommended (6).

The most commonly accepted course of treatment of appendicitis is appendectomy, although there is increasing research on the non-operative management of this condition (10). In the open technique, an extension of the incision would be required after finding that the appendix is in an abnormal position. The most valuable diagnostic tool in the management of suspected appendicitis is laparoscopy, particularly in women of child-bearing age (13).

\subsection{Conclusion}

Acute appendicitis remains one of the most common diseases treated by general surgeons. The subhepatic position of the appendix may cause a diagnostic dilemma due to its non-classical presentations. High index of clinical suspicion, good clinical knowledge of the surgeon, and utilisation of radio-imaging may help in the early diagnosis of the disease.

\section{Footnotes}

Authors' Contribution: Ranjan Kumar and Thokchom Biswajit Singh were involved in the surgical management, conceptualizing the study, and data collection. Ranjan Kumar and Rahul Pandey were involved in manuscript preparation. Sandeep Bhalla was involved in the final manuscript approval.

Conflict of Interests: It was not declared by the authors.

Funding/Support: This study was not funded by any organization or institution.

Informed Consent: It was taken from all the patients. 


\section{References}

1. Shirah BH, Shirah HA, Alhaidari WA, Abdulbagi OE. Challenges in the management of subhepatic acute appendicitis in the emergency setting. Int J Cur Res Rev. 2016;8(6):47-52.

2. Ball WR, Privitera A. Subhepatic appendicitis: A diagnostic dilemma. BMJ Case Rep. 2013;2013. doi: 10.1136/bcr-2013-009454. [PubMed: 23605843]. [PubMed Central: PMC3645804].

3. Williams N, O'Connell PR. Bailey \& Love's short practice of surgery. Florida, USA: CRC Press; 2008.

4. Schumpelick V, Dreuw B, Ophoff K, Prescher A. Appendix and cecum. Embryology, anatomy, and surgical applications. Surg Clin North Am. 2000;80(1):295-318. doi: 10.1016/s0039-6109(05)70407-2. [PubMed: 10685154].

5. King A. Subhepatic appendicitis. AMA Arch Surg. 1955;71(2):265-7. doi: 10.1001/archsurg.1955.01270140113021. [PubMed:14397970].

6. Palanivelu C, Rangarajan M, John SJ, Senthilkumar R, Madhankumar MV. Laparoscopic appendectomy for appendicitis in uncommon situations: The advantages of a tailored approach. Singapore Med J. 2007;48(8):737-40. [PubMed: 17657381].

7. Linder $\mathrm{HH}$. Embryology of gastrointestinal tract. In: Linder $\mathrm{HH}$, editor. Clinical anatomy. Connecticut, USA: Appleton \& Lange; 1989.

8. Galván-Montaño A, Flores-Nava G, Suárez-Roa Mde L, Salazar-Herrera MC, Lavalle-Villalobos A. Subhepatic appendicitis with subdiaphrag- matic abscess in a pediatric patient without intestinal malrotation: Case report. Cir Cir. 2010;78(1):79-81.

9. Kraemer M, Franke C, Ohmann C, Yang Q; Acute Abdominal Pain Study Group. Acute appendicitis in late adulthood: incidence, presentation, and outcome. Results of a prospective multicenter acute abdominal pain study and a review of the literature. Langenbecks Arch Surg. 2000;385(7):470-81. doi: 10.1007/s004230000165. [PubMed: 11131250].

10. Fasen G, Schirmer B, Hedrick TL. Appendix. In: Yeo CJ, editor. Shackelford's surgery of the alimentary tract. Philadelphia, USA: Elsevier Health Sciences; 2017. p. 1950-6.

11. Pieper R, Kager L, Nasman P. Acute appendicitis: A clinical study of 1018 cases of emergency appendectomy. Acta Chir Scand. 1982;148(1):51-62. [PubMed: 7136412].

12. Yacoe ME, Jeffrey RB. Sonography of appendicitis and diverticulitis. Radiol Clin North Am. 1994;32(5):899-912. [PubMed: 8085003].

13. Zinner MJ, Ashley SW. Maingot's abdominal operations. 12th ed. New York, USA: Mc Graw Hill Medical; 2013. p. 585-610.

14. Fuchs JR, Schlamberg JS, Shortsleeve MJ, Schuler JG. Impact of abdominal CT imaging on the management of appendicitis: An update.J Surg Res. 2002;106(1):131-6. doi: 10.1006/jsre.2002.6441. [PubMed:12127818].

15. Holloway JA, Westerbuhr LM, Chain J, Forney GA, White TW, Hughes RJ, et al. Is appendiceal computed tomography in a community hospital useful? Am J Surg. 2003;186(6):682-4. doi: 10.1016/j.amjsurg.2003.09.004. [PubMed: 14672779]. 